\title{
Mudanças ambientais globais e segurança humana: interpretações sobre pobreza, vulnerabilidade, risco e conflito
}

\author{
Global Environmental Change and Human Security: \\ Interpretations of Poverty, Vulnerability, Risk and Conflict
}

\author{
Rafael D'Almeida MARTINS*
}

\begin{abstract}
MATTHEW, R. A.; BARNETT, J.; MCDONALD, B.; O’BRIEN, K. L. (Orgs.). Global Environmental Change and Human Security. Massachusetts: MIT Press, 2010. 326 p. ISBN 978-0-262-01340-6.
\end{abstract}

\section{Apresentação}

A obra Mudança ambiental global e segurança humana baseia-se no programa de pesquisa de mesmo nome (cuja sigla é GECHS em inglês), fundado em 1996, que cresceu como uma rede global de investigação com o apoio do International Human Dimensions Programme on Global Environmental Change (IHDP). O livro em questão, composto de 15 capítulos distribuídos em cinco partes, com mais de 300 páginas, reúne um amplo conjunto de abordagens, marcos teórico-metodológicos e resultados de investigações de pesquisadores associados ao GEGHS, representando alguns dos principais resultados da rede em mais de uma década de atuação. Os capítulos do livro, que apresentam tanto rigor científico quanto relevância política, discutem desde as relações entre processos ambientais globais e a pobreza urbana até o impacto de desastres naturais e os conflitos violentos na população. Ao longo de suas páginas, saltam aos olhos do leitor abordagens alternativas que buscam preencher lacunas na literatura que falham ao não apresentar modelos conceituais e teóricos que contri- buem para analisar os desafios do século XXI, marcado por situações de insegurança humana e conflito, além da necessidade de novas formas de cooperação, governança e desenvolvimento sustentável. Dessa forma, a presente resenha pretende levantar questões que são tanto objeto de análise e reflexão no livro como também relevantes para a discussão e o avanço da área de pesquisa sobre ambiente e sociedade no Brasil.

\section{Segurança humana no século XXI}

O livro responde ao crescente consenso existente de que mudanças ambientais globais, tais como a elevação do nível do mar, o aumento da erosão costeira e as mudanças nos padrões de temperatura e precipitação, além do possível aumento dos extremos climáticos, são desafios significativos para a segurança humana apesar de visões conflitantes sobre o que possa ser e o que constitui essa noção de segurança para os seres humanos. A definição de segurança humana adotada pela rede e, consequentemente, apresentada no livro, é baseada em uma construção centrada

\footnotetext{
"Administrador Público (FGV-EAESP). Doutorando em Ambiente e Sociedade, Núcleo de Estudos e Pesquisas Ambientais (NEPAM), Universidade Estadual de Campinas (UNICAMP). Coordenador da Rede de Pesquisadores do Earth System Governance Project (ESG), International Human Dimensions Programme on Global Environmental Change (IHDP). Email: rdamartins@gmail.com
} 
no bem-estar de pessoas e comunidades, indo além de visões costumeiras focadas em governos ou no próprio Estado.

Tal definição busca, assim, uma integração analítica das várias dimensões da segurança humana, como, por exemplo, a garantia das necessidades básicas, dos direitos e das responsabilidades, priorizando a justiça social. Enfatiza-se que a segurança humana pode facilitar as formas pelas quais indivíduos e comunidades respondam melhor à mudança ambiental, aumentando sua resiliência. A ideia de segurança humana torna-se também importante em termos da mudança ambiental, uma vez que pode ajudar a identificar impactos e responder às consequências destes sobre aqueles que estão mais diretamente expostos à mudança, dando vozes aos mais vulneráveis e chamando a atenção de pesquisadores e tomadores de decisão para esses fenômenos.

O vasto domínio da área de pesquisa determinada pela "segurança ambiental" emergiu a partir da intersecção de duas importantes ideias-forças e áreas de intervenção governamental, respectivamente a segurança e o meio ambiente. O livro destaca que essas ideias são constantemente debatidas por conta de sua natureza ambígua, levando a diferentes interpretações do que segurança ambiental pode significar, tanto na teoria como na prática. Da mesma forma, a noção de segurança humana que é defendida no livro também foi alvo de críticas e diferentes definições e abordagens para segurança humana foram propostas e discutidas empiricamente na última década (i.e. PAGE, 2000; BARNETT; ADGER, 2007, entre outros).

Independentemente das críticas ou das diferentes formulações propostas, torna-se importante visualizar de que forma essas estão totalmente interconectadas, lançando luz sobre a natureza dos novos desafios deste século - marcados pela complexidade, pela fragmentação e pelo poder da ação humana sobre o planeta Terra. Nesse contexto, as escalas do consumo e da poluição ambiental na sociedade moderna têm sido vetores fundamentais de uma série de mudanças ambientais, como as observadas quando se analisa a taxa de cobertura florestal, a perda de biodiversidade, a drástica redução dos estoques de determinados peixes, a degradação do solo, a poluição e a escassez de água, além da contaminação de pessoas, plantas e animais por produtos químicos e substâncias radioativas, entre muitas outras mudanças, que contribuem para o que Beck (1992) chamou de sociedade de risco em sua obra seminal.

\section{Mudança climática, urbanização e globalização como desafios sem precedentes para a segurança humana}

Em abril de 2007, o Painel Intergovernamental para a Mudança do Clima (sigla IPCC em inglês) divulgou a segunda parte de seu Quarto Relatório de Avaliação, repercutindo no mundo inteiro dada a seriedade dos dados e análises apresentados que, apesar de ainda suscitarem calorosas disputas científicas e políticas, defende com grande confiança que os mais pobres serão aqueles que sofrerão os efeitos da mudança climática de forma mais aguda (IPCC, 2007, p. 9). Nesse sentido, a segurança humana adquire um significado mais amplo quando se consideram as necessidades básicas de alimentação, água, saúde, educação e direitos. A mudança climática coloca na agenda internacional novas ameaças e crescentes desafios à segurança humana.

Entre os vetores de mudança mais poderosos da atualidade estão a urbanização, a globalização e a acelerada mudança ambiental, sobretudo em termos do sistema climático global. Com mais da metade da população mundial habitando áreas urbanas desde o ano de 2008 (no Brasil, essa proporção é superior a $80 \%$ ), as consequências dessas mudanças são marcadas por profunda incerteza e indeterminação na escala local (RIBEIRO, 2008). Tais mudanças ambientais estão em toda parte e muitas apresentam causas e consequências globais, como no caso dos gases de efeito estufa (WILBANKS; KATES, 1999). No entanto, apesar do alcance das mudanças ambientais globais, isso não significa dizer que todos compartilham a mesma responsabilidade, nem que os impactos das mesmas são igualmente distribuídos entre diferentes lugares e pessoas. Ao contrário, a natureza global das mudanças refere-se às relações e às interdependências entre a mudança ambiental e suas consequências sociais para os lugares, as pessoas e o planeta (BIERMANN et al., 2009).

Nesse sentido, vetores de mudança e as mudanças em si adquirem significados sem precedentes nesse século. Os desafios urbanos em termos da segurança humana - e quando se leva em conta o contexto das mudanças climáticas nas cidades mundiais - deixam claro que as áreas urbanas podem ser, ao mesmo, causa e solução dos problemas globais. A concentração de pessoas, infraestruturas e capital configura as oportunidades de avançar na direção da sustentabilidade, ao mesmo tempo em que atividades e padrões de desenvolvimento urbanos colocam inúmeras pressões 
sobre os recursos naturais. Estimativas e projeções, tanto das Organizações das Nações Unidas (ONU) como do Banco Mundial (BM) e do IPCC, mostram que as tendências de urbanização, globalização e mudança do clima, sobretudo nos países periféricos, deve avançar nas próximas décadas. Essa inter-relação entre mudança climática, urbanização e globalização econômica pode contribuir para o que O’Brien e Leichenko (2000, p. 222) chamaram de dupla exposição, ou seja, o fato de que pessoas, comunidades, regiões, setores e ecossistemas estão sendo confrontados ao mesmo tempo, tanto pelos impactos da mudança climática quanto pelas consequências da urbanização e globalização (ver também Leichenko e O’Brien, 2008).

\section{O livro em detalhes}

Esta realidade está influenciando novas visões em todo o mundo, uma vez que se percebe, com cada vez mais clareza, que o futuro da segurança humana está sendo profundamente afetado por processos locais e globais de desenvolvimento (in)sustentável e mudança ambiental. Dessa forma, o livro Global Environmental Change and Human Security, organizado por Richard Matthew, Jon Barnett, Bryan McDonald e Karen L. O'Brien, todos estudiosos de renome internacional, é uma importante e oportuna contribuição para esse campo emergente e necessário de pesquisa e política pública no qual o Brasil e a América Latina, assim como muitos outros países em desenvolvimento, apresentam experiências pontuais e pouca tradição acadêmica e científica.

O livro está organizado em cinco partes. A primeira refere-se à Introdução, com apenas um capítulo. A parte II tem quatro capítulos sobre mudanças ambientais globais e insegurança humana, explicando as formas pelas quais a mudança ambiental compromete a segurança humana, fornecendo marcos de análise para esses processos e suas interconexões. A parte III, denominada Mudança Ambiental Global, Conflitos e Cooperação, é composta por dois capítulos que chamam a atenção para as relações entre mudança ambiental, segurança humana, paz e conflitos, especialmente os violentos, revisando a literatura e as evidências de um estudo de caso. Já os sete capítulos da parte IV, intitulada Segurança Humana e Desenvolvimento Sustentável, focam nas relações entre desenvolvimento sustentável e segurança humana, apresentando discussões sobre temas transversais como gênero e população, destacando a interação entre desenvolvimento e segurança ambiental.
A seguir, apresentam-se os capítulos do livro explorando como a mudança ambiental global desafia a segurança humana para além da dicotomia entre ricos e pobres. Os capítulos buscam destacar como a mudança ambiental confronta a segurança de pessoas e comunidades com a segurança de ecossistemas e espécies, incluindo a humana. O livro ressalta, dessa maneira, que a mudança ambiental global é também uma questão da capacidade de responder aos novos desafios que estão colocados neste século, trazendo para o centro do debate as crescentes desigualdades que ameaçam a segurança humana.

$\mathrm{Na}$ Introdução do livro (parte I, capítulo 1), Barnett et al. buscam conceituar o surgimento desse campo de investigação a partir de uma análise da política e do discurso. A articulação entre mudanças ambientais globais e segurança humana não tem recebido a atenção esperada da comunidade científica, apesar dos riscos à segurança humana representados por muitas das mudanças ambientais, especialmente hoje, face aos desafios colocados pelo aquecimento global e pelas mudanças climáticas, além de várias outras mudanças, que têm sido sistematicamente avaliadas e monitoradas por painéis de especialistas e instituições internacionais como o Painel Intergovernamental sobre Mudança Climática (IPCC), a Convenção-Quadro das Nações Unidas sobre Mudança do Clima (UNFCCC) e o Millennium Ecosystem Assessment (MEA).

No início da parte II, o capítulo 2 fornece um marco conceitual para avaliar trajetórias de mudança ambiental global que fazem determinadas populações mais vulneráveis, mesmo quando elas criam novas oportunidades para outros grupos. Os autores defendem que vulnerabilidade e insegurança são condições subjacentes para comunidades onde a mudança ambiental global é apenas uma ameaça, trazendo a necessidade de um equilíbrio entre a exposição a riscos vis-à-vis com a capacidade de responder às ameaças que estão colocadas pelos novos contextos. O capítulo 3 destaca um mundo cada vez mais interconectado, onde indivíduos infectados por doenças contagiosas podem disseminar uma epidemia pelo mundo em poucas horas. Nesse sentido, a mudança ambiental global exacerba os problemas e os riscos de doença através de alterações em temperaturas ou em ecossistemas. Já o capítulo 4 examina as relações entre urbanização e mudanças ambientais. Enquanto o mundo veio passando por um intenso processo de urbanização no último século, especialmente nos países em desenvolvimento, os autores ressaltam que a mudança ambiental pode exacerbar inseguranças já vividas pelas 
populações pobres em centros urbanos, principalmente por causa do acesso restrito a serviços necessários para se adaptarem a uma nova situação. O capítulo discute em detalhes os aspectos da vida dos moradores de favelas, que poderão ser os mais afetados pelas mudanças climáticas em áreas urbanas. Os autores concluem que as soluções para os complexos impactos dessas mudanças sobre esta população vulnerável passam pela análise política e econômica das barreiras que limitam as oportunidades de favelados em melhorar suas vidas. No capítulo 5, o caso do furacão Katrina em Nova Orleans é discutido em uma perspectiva histórica e fatual. O capítulo conclui que falhas em políticas urbanas e ambientais tornaram várias pessoas mais vulneráveis ao desastre. Partindo deste ponto de vista, o autor argumenta que foi a falta de preparação por parte da população e do governo, em seus diferentes níveis, que levaram à destruição da cidade, desmascarando de forma visceral as desigualdades sociais daquela localidade. Dessa forma, não foi só a exposição ao risco ambiental que provocou o desastre, mas também vulnerabilidades decorrentes de processos sociais, políticos e econômicos.

A parte III começa com o capítulo 6, que se baseia em trabalhos anteriores para verificar como a mudança ambiental afeta negativamente a segurança humana e, em seguida, os autores argumentam que essa insegurança humana pode, em certas circunstâncias, aumentar o risco de conflitos violentos. Eles examinam as múltiplas formas em que a insegurança humana, exacerbada pela mudança ambiental, pode criar ou reforçar condições para um conflito violento. No capítulo 7, seguindo esse tema, ilustra-se a relação entre mudança ambiental e conflitos violentos por meio de um estudo de caso da guerra civil no Nepal. Os autores mostram como estresses ambientais foram uma das principais causas dos conflitos violentos nesse país, apontando para efeitos sobre a dinâmica demográfica e o uso do solo.

$\mathrm{Na}$ parte IV, o capítulo 8 destaca questões de equidade em torno tanto de mitigação quanto de adaptação às mudanças ambientais globais. Essas dimensões de equidade devem ser abordadas ao buscar-se uma segurança humana reforçada. Respostas com base em valores de equidade referem-se aos vários processos e fatores que influenciam a vulnerabilidade e a capacidade adaptativa, reconhecendo que a mudança ambiental não é simplesmente um problema de origem Norte-Sul ou uma questão de diferenças entre países ricos e pobres, mas um problema que cruza fronteiras nacionais e precisa ser tratado de forma abrangente, em diferentes escalas e unidades de análise. O capítulo 9 analisa possíveis respostas à mudança ambiental global, olhando para a história como forma de compreender esforços orientados para dar respostas e gerenciar mudanças ambientais. $\mathrm{O}$ autor conclui que as melhores respostas são aquelas de caráter planejado e não as meramente reativas, enfatizando que sociedades e governos com capacidade de se preparar para enfrentar para as mudanças ambientais devem auxiliar aqueles com menor capacidade. $\mathrm{O}$ capítulo 10 investiga a recorrente abordagem de algumas correntes científicas de países desenvolvidos, que vislumbram uma crise malthusiana - onde a população ultrapassaria a disponibilidade de recursos em termos globais. Esta ênfase no controle populacional e nos perigos de uma superpopulação vem influenciando negativamente políticas públicas e reforçando estereótipos de uma explosiva e crescente população do Terceiro Mundo. No capítulo 11, examina-se o impacto da mudança ambiental global sobre a segurança das mulheres. Com base em abordagens de gênero e desenvolvimento, o autor argumenta que as mulheres são particularmente vulneráveis às mudanças ambientais, assim como elas têm o potencial de preservar e proteger recursos naturais. $\mathrm{O}$ capítulo sugere uma abordagem baseada em gênero para a segurança ambiental. $\mathrm{O}$ capítulo 12 descreve as várias formas em que a segurança humana se relaciona com o desenvolvimento sustentável. Ele mostra que a redução da pobreza, a prevenção de conflitos e o controle das mudanças ambientais não são apenas objetivos fundamentais para a segurança humana, mas também são importantes precursores para o desenvolvimento sustentável. O capítulo 13 avança na compreensão das interfaces entre desenvolvimento e segurança humana ao investigar a relação dessas questões com o fortalecimento da democracia. Ao afirmar que o desenvolvimento econômico, para ser sustentável, não pode ser apenas crescimento, mas sim uma evolução na forma como uma sociedade utiliza recursos naturais para proteger sua população atual e futura contra desastres e privações, os autores concluem que níveis mais elevados de democracia estão relacionados a um nível maior de desenvolvimento, que configuram sociedades menos vulneráveis e com maior segurança humana. No capítulo 14, a internacionalização dos problemas ambientais e suas soluções é explorada com base em estudos de casos sobre o uso e manejo de duas áreas de recursos regionais na América Latina, o Corredor Biológico Mesoamericano e a Bacia do Prata. A cooperação entre Estados sobre esses recursos é um desafio à soberania nacional, tal como ela é apresentada na Ordem Westphaliana. As preocupações ambientais que 
transcendem aos limites de Estados nacionais têm chamado a atenção para os benefícios da cooperação na gestão desses recursos, conforme é apresentado em detalhes pelo autor. Na parte V, o último capítulo denominado Charting the Next Generation of Global Environmental Change and Human Security Research, os autores esboçam diretrizes futuras para a pesquisa e as implicações das mudanças ambientais globais para a segurança humana.

\section{Para não concluir}

O livro é rico em temas e apresenta diferentes pontos de vista, inclusive algumas vezes até mesmo conflitantes, sobre a mudança ambiental e a segurança humana. Tal debate é importante, pois está levantando algumas questões que são fundamentais para o século XXI. A mudança ambiental global está conduzindo a uma nova compreensão da noção de segurança, destacando que as abordagens atuais são limitadas e oferecem bases inadequadas para apoiar processos de tomada de decisão e políticas públicas. O livro deixa claro que diferentes graus de mudança ambiental são um risco para pessoas, lugares e a estabilidade do planeta. Com base nisso, os capítulos defendem um interesse maior sobre as formas como diferentes sociedades estão se organizando e como elas aplicam formas variadas de tecnologia, conhecimento e sistemas de governança que configuram meios de subsistência e estilos de vida ao redor do mundo.

Do outro lado, o livro também traz para o centro do debate as áreas urbanas. Essas deverão ser o foco da pesquisa sobre mudanças ambientais globais neste século, diferentemente do que foi feito até a última década, onde as áreas rurais receberam mais atenção dos pesquisadores. Espera-se que os impactos mais agudos da mudança do clima sejam sentidos nas áreas urbanas, ameaçando pessoas, infraestruturas e colocando em risco o desenvolvimento econômico mundial. Nesse sentido, o desafio também está em chamar a atenção para esses problemas, focando na relação entre mudanças ambientais globais e segurança humana, o que não foi realizado e não tem sido feito até o momento. Existe carência de estudos que abordam essas questões em áreas urbanas, trazendo a necessidade de mais trabalhos para cobrir essas lacunas. Para isso, torna-se fundamental que existam esforços de pesquisa coordenados, trazendo para análise uma visão holística desses processos. Apesar de abordagens disciplinares e tradições acadêmicas especificas, o livro em questão dá uma importante contribuição na direção desse campo interdisciplinar de investigação.

Nesse sentido, conforme afirma Geoffrey D. Dabelko no prefácio do livro, "Global Environmental Change and Human Security é uma leitura obrigatória" para pesquisadores e estudiosos da área de ambiente e sociedade nas suas diferentes comunidades científicas. Esta obra abre novos caminhos para compreensão de vários dos problemas atuais e futuros que estão na agenda da sociedade civil e dos governos. Dessa forma, esse livro - que é resultado da colaboração entre pesquisadores, ativistas e tomadores de decisão - fornece novas ideias e marcos de análise que poderão guiar a busca de algumas soluções para os desafios deste século.

\section{Referências}

BARNETT, J.; ADGER, W.N. Climate change, human security and violent conflict. Political Geography, n. 26, p. 639-655, 2007.

BECK, U. Risk Society. Beverly Hills: SAGE Publishing, 1992.

BIERMANN, F.; BETSILL, M. M.; GUPTA, J.; KANIE, N.; LEBEL, L.; LIVERMAN, D.; SCHROEDER, H.; SIEBENHÜNER, B.; CONCA, K.; FERREIRA, L. C.; DESAI, B.; TAY, S.; ZONDERVAN, R. Earth System Governance: People, Places and the Planet. Science and Implementation Plan of the Earth System Governance Project. Earth System Governance Report 1, IHDP Report 20. Bonn: IHDP, The Earth System Governance Project, 2009.
IPCC - INTERGOVERNMENTAL PANEL ON CLIMATE CHANGE. Summary for Policymakers. In: PARRY, M. L.; CANZIANI, O. F.; PALUTIKOF, J. P.; VAN DER LINDEN, P. J.; HANSON, C. E. (Eds.). Climate Change 2007: Impacts, Adaptation and Vulnerability. Contribution of Working Group II to the Fourth Assessment Report of the Intergovernmental Panel on Climate Change. Cambridge: Cambridge University Press, UK, p. 7-22, 2007.

LEICHENKO, R. M.; O'BRIEN, K. L. Environmental Change and Globalization: Double Exposures. New York: Oxford University Press, 2008. 167 p. 
MARTINS, Rafael D’Almeida. Mudanças ambientais globais e segurança humana: interpretações...

O'BRIEN, K. L.; LEICHENKO, R. M. Double exposure: assessing the impacts of climate change within the context of economic globalization. Global Environmental Change, n. 10, p. 221-232, 2000.

PAGE, E. Theorizing the link between environmental change and security. Reciel, n. 9, p. 33-43, 2000.
RIBEIRO, W. C. Impactos das mudanças climáticas em cidades no Brasil. Parcerias Estratégicas, v. 27, p. 297-321, 2008.

WILBANKS, T.; KATES, R.W. Global Change in Local Places: How Scales Matters. Climatic Change, n. 43, p. 601-628, 1999.

Recebido em maio de 2010

Aceito em julho de 2010.

Publicado em dezembro de 2010. 